This item was submitted to Loughborough's Research Repository by the author.

Items in Figshare are protected by copyright, with all rights reserved, unless otherwise indicated.

\title{
Cutting cost in service systems: are you running with scissors?
}

PLEASE CITE THE PUBLISHED VERSION

http://dx.doi.org/10.1002/jsc.1981

\section{PUBLISHER}

(c) John Wiley \& Sons, Ltd

\section{VERSION}

AM (Accepted Manuscript)

\section{PUBLISHER STATEMENT}

This work is made available according to the conditions of the Creative Commons Attribution-NonCommercialNoDerivatives 4.0 International (CC BY-NC-ND 4.0) licence. Full details of this licence are available at: https://creativecommons.org/licenses/by-nc-nd/4.0/

\section{LICENCE}

CC BY-NC-ND 4.0

\section{REPOSITORY RECORD}

Thenent, Nils E., Ettore Settanni, Glenn Parry, Yee M. Goh, and Linda B. Newnes. 2019. "Cutting Cost in Service Systems: Are You Running with Scissors?”. figshare. https://hdl.handle.net/2134/17066. 


\section{Cutting cost in service systems: Are you running with} 2 scissors? ${ }^{1}$

3 Nils E. Thenent

4 Department of Mechanical Engineering, University of Bath, Bath, United Kingdom

5 Ettore Settanni

6 Department of Mechanical Engineering, University of Bath, Bath, United Kingdom

7 Glenn Parry

8 Faculty of Business \& Law, University of the West of England, Bristol, United Kingdom

9 Yee Mey Goh

10 Wolfson School of Mechanical and Manufacturing Engineering, Loughborough

11 University, Loughborough, United Kingdom

12 Linda B. Newnes

13 Department of Mechanical Engineering, University of Bath, Bath, United Kingdom

14 Correspondence to:

15 Nils E. Thenent

16 Department of Mechanical Engineering

17 University of Bath

18 Claverton Down Campus

19 Bath, BA2 7AY

20 United Kingdom

21 e-mail: N.E.Thenent@bath.ac.uk

\footnotetext{
${ }^{1}$ J.E.L. classification codes: D21 (Firm Behavior); D83 (Search; Learning; Information and Knowledge; Communication; Belief);M21 (Business economics); Z10 Cultural Economics; Economic Sociology; Economic Anthropology: General; B41 (Economic Methodology);

E.F.M. classification codes: 760 (Methodological issues)
} 
23

A rigorous link between the domains of cost estimation, systems theory and accident investigation reveals fundamental epistemological limitations of commonly employed cost models when dealing with the characteristics of systems, particularly service systems, which may hinder the ability to take appropriate action for cost reductions.

\section{Key points:}

1. The ability to take action, in particular related to cost reductions in service systems, is strongly influenced by the understanding (epistemological assumptions) underlying a decision-support tool, in this case a cost estimate.

2. A managerial perspective of cost estimation which neglects the essential characteristics of service systems may drive behaviour which is locally optimised but creates tension or failure at the system level.

3. Cost cutting decisions that are based on a flawed understanding of the situation can lead to counter-intuitive outcomes for organisations; hence practical guidance is needed to help managers consciously consider the underlying epistemological assumptions in a given situation. 
A desire for cost savings is often identified by key executives as leading customers to adopt services offered by organisations that have 'servitized' (Aston Business School, 2013). Yet, as identified in this article through a systemic theoretical insight, there are potentially disruptive mismatches between 1) the nature of the delivery systems underpinning the innovative service offering in companies that have servitized and 2) the methodological foundations of the approaches for the evaluation of the costs associated with these systems for decision making purposes. Statements such as "Customers of servitization are reducing costs by up to 25-30\%" are based upon subjective judgments and many key questions are not addressed such as 'which cost is meant?', 'how are costs determined?' and 'for what purpose was the cost computed?'. In the defence sector servitization frequently translates into contractual arrangements to guarantee asset-related performance, particularly asset availability. Claims related to the cost-effectiveness of these arrangements, which may eventually result in their practical implementation, are often made in the absence of sound business model analyses (GAO, 2008). In such cases as, for example, Pratt \& Whitney's F117 engines powering the US Air Force's fleet of C-17A airlifters there has been a move back to transactional approaches to maintenance in the hope that more competition in the support contract bidding phase drives prices down (Trimble, 2013). However, it is acknowledged that in times of pressure on defence budgets apparently straightforward initiatives for saving money may prove ineffective since they compromise the ability to deliver capability when needed. For example, cuts in training and maintenance, reduction of force structure and cancellations of equipment programs which are already under way may eventually drive up an asset's unit cost (Chinn, 2013). In the public eye, cost tends to be addressed as something to fear and forecast (much as an adverse meteorological event), not something to understand and manage. This is particularly evident, for example, in the case of the F-35 Joint Strike Fighter (Coghlan, 2012, Fulghum et al., 
2011). Cost estimators and modellers in turn have long been concerned with predicting how much something costs using aggregate data and drawing on past experience of cost outturns, rarely asking why it will cost that much (Dean, 1993). This approach may give the impression that progress in understanding and controlling cost is being made despite the fact that the problem is only partially understood. The drawback in cost prediction for projects is typically a "fire fighting" approach to project problem resolution, resulting in a chance that, as and when the desired results are delivered, the asset is provided late and at a higher cost than planned (Burge, 2010).

This article suggests that the key to address these concerns is to build on a defensible conceptual representation of the socio-technical system underlying successful service delivery, as an integral part of the cost estimating process. This is demonstrated through a transdisciplinary research approach, characterised by problem focus, evolving methodology and collaboration (Wickson, Carew \& Russell, 2006). The problem at stake is that the methodological choices in costing advanced services, such as availability or other types of performance, delivered through a product-service-system may hinder rather than raise cost consciousness for informed decision making. A methodology to face such a problem has to respond to and reflect the specific problem and context under investigation. The development of such methodology, which is discussed in this paper, is through collaboration between authors having different expertise, and dialogue with industrial and institutional stakeholders.

The remainder of the paper discusses the characteristics of service systems, their associated costs and different perspectives on costs. A clarification of the links between action and understanding leads to the identification of an epistemological conflict in the perception of cost in service systems. It is concluded that epistemology is highly relevant for managerial decision making. Finally, future and on-going work is outlined. 


\section{Why service systems have their peculiarities}

91 Manufacturers that have 'servitized' offer advanced services that are critical to their

92 customers' core business processes through incentivised contracting mechanisms such as availability or performance-based contracts. For these providers servitization involves innovation of their internal capabilities in operations, and the service delivery system is just as important as the service offering itself (Baines \& Lightfoot, 2013). This section provides theoretical insight into such a service delivery system from a 'system thinking' perspective, highlighting the aspects that may be a challenge for costing advanced services.

\subsection{Seeing Service System as 'systems'}

Advanced services are delivered by a "knowledge-intensive socio-technical system" sometimes referred to as Product Service System (Meier, Roy \& Seliger, 2010; Baines \& Lightfoot, 2013). A PSS being a particular case of system it exhibits common characteristics of systems (Blanchard, 2008, Wasson, 2006, Burge, 2010), in particular:

c) It has a purpose.

Also, a PSS is a special case of service systems. According to Wang et al. (2013) service systems exhibit distinguishing features such as a network infrastructure; a substance (the types of which include material, human/animal, energy and knowledge) flowing over such an infrastructure; and a protocol for the management (coordination, leading, planning and control) of both the structure and the substance.

111 Central to the concept of a service system is that it enables the customer to attain a result, or

112 beneficial outcome, through a combination of activities and resources, including assets, to 113 which both the service provider and the customer contribute (Ng et al., 2011). 
115 Service systems are socio-technical systems due to the coexistence of physical and human components. This has long suggested that service system analysis should be approached as a social construction and that their technical representation should contain indications about potential functions, interaction between actors and functionalities and flows of events

119 (Morelli, 2002).

Whilst methodologies like System Engineering aim at deriving possible solutions by applying techniques to a well-defined problem, a defensible intellectual process of thinking about a socio-technical system has to start by defining, not a problem but a situation that is problematic (Wilson, 2001). Dekker (2011) highlights the difficulty, when analysing a sociotechnical system, of clearly identifying what is actually affected by an action and what is not. Hence, the boundaries between the "system of interest" (Wasson, 2006) and the exogenous components that affect or are affected by it (that is, the environment) should be determined by the purpose of the system description (what shall be examined and why), not by the system itself.

Drawing the system boundaries allows a distinction between what are deemed uncontrollable external events (originating with the environment) and controllable internal events. The former are the subject of "forecasting" whilst the latter are the subject of "decision making" 132 (Makridakis, Wheelwright \& Hyndman, 1998). In the context of 'servitization' the boundary defining lens is the enterprise, which "imposes a holistic management or research perspective on a complex system of interconnected and interdependent activities undertaken by a diverse network of stakeholders for the achievement of a common significant purpose" (Purchase et al., 2011). However, only when all stakeholders involved share a common interest in taking action towards a common purpose - also by sharing financial information and insight of each other's processes (Romano \& Formentini, 2012) - does the enterprise provide a reasonable 
scope for the analysis. An in-depth discussion of how to create potentially efficient governance relations within the enterprise in the presence of stakeholders with heterogeneous goals is beyond the scope of this paper. The interested reader is referred to (Tirole, 2001) for a theoretical baseline, and (Kim, Cohen \& Netessine, 2007) for a specific discussion concerning availability-based contracts.

In socio-technical systems there is no reasonable prospect of gaining complete knowledge about the whole system (Hollnagel, 2012). Hence, local decision-making is always based on incomplete knowledge about the whole system and actions undertaken to optimally fulfil locally visible goals are prone to manifest in global system tensions or even failure (Snook, 2002, Dekker, 2011).

\subsection{Service systems exhibit emergent properties}

Importantly, it is not possible to deduce the properties and behaviour of the whole system from the properties and behaviour of its constituting elements in isolation (Burge, 2010). This has significant implications for the investigation of a system and its components as it excludes the possibility of capturing and superimposing individual components' characteristics to successfully describe the total system. Only when brought together and interacting with each other do emergent properties arise (Dekker, 2011, Burge, 2010). These may not even be predicable when looking at the complete system as their occurrence is based upon relationships between the components that may not be known, or knowable (Dekker, 2011). Some of these relationships may be intended or not, they may however only exist temporarily and can therefore be difficult or impossible to comprehend (Perrow, 1984). Hence, an understanding can only be acquired when the system is examined over time, and any investigation of a system can only provide a snapshot in time. In principle, this applies to cost as well - for example, through the concept of 'cost image' (Lindholm \& Suomala, 2007). 
164 There are multiple ways of approaching socio-technical systems. Bartolomei et al. (2012) provide an overview and framework. In the authors' opinions, however, the field of accident investigation provides insight into socio-technical systems that can be of particular interest for the analysis of service systems. Both domains are concerned with outcomes: accident investigation focuses on undesired outcomes in the form of accidents or incidents, where service systems deal with doing something 'right' from the customer viewpoint (hence delivering value in-use) or dealing with the consequences of failing to do so.

Two outstanding contributions in the field of accident investigation relate to large-scale multiorganisational delivery systems that produced highly undesired outcomes: "The Challenger Launch Decision" (Vaughan, 1997) deals with the explosion of the Challenger Space Shuttle shortly after lift-off in 1986. "Friendly Fire" (Snook, 2002) concerns the shooting down of two U.S. Army helicopters by two U.S. Air Force fighter jets in 1994. Both works were motivated by the lack of insight the preceding investigations were able to provide. The failure to send a shuttle into space and return it safely back to earth was attributed to a single malfunctioning component and the conditions for such component being "allowed" to malfunction were blamed on flawed decision making processes and individual managers making the wrong decisions (Vaughan, 1997). Vaughan contradicts these findings and gives insights into why people have acted in the way they did and what the information available at the time before the launch meant to those involved. In this way she provides a much more elaborate analysis of the systemic conditions that enabled the outcome. In the other example, the failure to provide safe transportation in northern Iraq, the official investigation could not show a single culprit or "smoking gun" (Snook, 2002). Snook's account of the events draws on detailed descriptions of the actions in their respective context. He concludes that to make sense of the events a wider view, across organisational boundaries, 
was required and that any analysis on a single level will miss the mechanism affecting the outcome.

A key lesson that can be learned from these analysis of socio-technical systems is that the way we look at phenomena not only influences, but determines what we are able to see and in the end determines what we are able to find (Dekker, 2006, 2011). This is also known as the "What-You-Look-For-Is-What-You-Find" principle (Hollnagel, 2012). Therefore, the model we apply in our view on the relationship between cost and the service system is a determinant for what we are able to find and ultimately do about it.

\section{Costing service systems}

A firm transforming to a role as service system provider is concerned with the cost of delivering results (Tukker \& Tischner, 2006). However, in sectors like defence, the emphasis is placed on quantifying how much has been spent in a certain time-span for the acquisition of capabilities, usually categorised aggregately according to their nature as labour, equipment, materials types etc. (Anagboso \& Spence, 2009). By setting the focus of cost analysis on the acquisition of the capabilities acquired (inputs), little or no insight is given at the level of accomplishment (outcomes) pursued as a result of a certain endeavour and its intermediate results (output) (Doost, 1996). A practical example is provided by a recent article on the UK tactical intelligence capabilities namely the Ministry of Defence (MoD)'s Watchkeeper unmanned air system (UAS) programme (Hoyle, 2013). First and foremost, the program is identified in terms of what has been spent on the procurement of a number of aircraft that were not operational. However, as the focus shifts on the target acquisition and reconnaissance services in Afghanistan, it becomes clear that for this to be achieved another UAS had to be leased. 
211 Categorising costs without considering the underlying demand for jobs to be done can be particularly insidious, as Emblemsvåg (2003) points out. This way of categorising provides no indication of whether a reduction of spending in any of these categories erodes the company's future ability to deliver value by meeting customer demand. This, in turn, may trigger more cost cutting - a phenomenon addressed as "death spiral" (Chinn (2013) provides an example concerning military-equipment acquisition). In a downturn, companies' intent of cutting costs may inadvertently result in damaging the fabric of their business by cutting "muscle" instead of "fat" (George, 2010, Coyne, Coyne \& Coyne, 2010).

A closer look at the direction taken in academia regarding how to cost services and service systems reveals that the approaches proposed so far lack orientation toward the results that a service system is meant to deliver (Settanni et al., 2011). Often, the cost of a service system is identified with the cost of the in-service phase of a durable product (see for example, Datta \& Roy, 2010, Huang, Newnes \& Parry, 2012, Jazouli \& Sandborn, 2011). Even when a systems approach is explicitly claimed in cost estimation, it is not the case that a representation and modelling of the system structure, elements and purpose explicitly play a role (see for example Hart et al., 2012, Valerdi, 2011). Approaches like Activity Based Costing have been recommended for the service industry, where the performance and cost of business processes, especially those experienced directly by customer, is crucial for competitive differentiation (Edwards, 1999, Rotch, 1990). The foundation of these approaches is a focus on activities or operations within the enterprise that are structured according to their logical order and dependence, and are aimed to produce a specific result which is of value to internal or external customers (Hansen \& Mowen, 2003). To the authors' knowledge, however, only Kimita et al. (2009) have proposed a service system costing model based on a representation of a functional service structure, where functions are 
realized by both human activities and product behaviours that are performed to deliver value with the customer.

The underlying principle is that costs cannot be managed - only activities can (McNair, 1990). Therefore, in this case a cost estimate is an attention focusing device (Cooper, 1990), raising cost consciousness by continuously monitoring the behaviour of the relevant cost over time

240 (Lindholm \& Suomala, 2007).

\section{$4 \quad$ What is your cost model?}

Cost modelling has been defined as an a priori analysis that maps the characteristic features of a product, the conditions for its manufacture and use into a forecast of monetary expenditures, irrespective from whom (provider, customer, etc.) the monetary resources will be required (Sandborn, 2013). An overview of issues and approaches in cost modelling is outside the scope of this paper and can be found elsewhere (Curran, Raghunathan \& Price, 2004). Here, "What is your cost model?" is a re-interpretation of the question "What is your accident model?" asked by Dekker (2006) to sensitise for the impact of our preferred view on what we are able to see.

\subsection{Cost is an intrinsic property of products}

A common view on cost is to assume that cost is a dependent variable that has the propensity to be related statistically to the technical attributes used by the designers to characterise a product or service instance, or other features of a project. This is the view adopted in parametric cost models (see for example, Pugh, Faddy \& Curran, 2010). The relationship between cost and these characteristics is typically one of statistical correlation, derived through extensive records of historical data. This model's use is typically focussed on speed of results, and allows changes in product's features through redesign to translate directly and immediately into changes in its unit cost. For example, Valerdi, Merrill \& Maloney (2005) adopt 
this model to calculate the yearly cost of an Unmanned Aerial Vehicle as a function of its payload weight and endurance.

This cost model implicitly reflects an assumption which is commonly made in the literature: a significant portion of a product's cost is locked-in at its design (commonly quoted statistics are typically beyond $80 \%$, see for example Newnes et al., 2008). This assumption suggests, even in the absence of empirical evidence, that focus should be on product development, whilst diverting attention away from actions that can be taken in manufacturing or other downstream activities including use (Cooper \& Slagmulder, 2004, Labro, 2006). Placing the responsibility for the costs incurred while the product is deployed exclusively on the designer creates the expectation that cost can be treated as an independent variable, just like any other engineering unit in the design process (see for example, Nicolai \& Carichner, 2010). Being based on a direct relationship between design features and cost (per unit, per year etc.), this cost model also promotes an idealised approach to product design which overlooks the challenge of cost allocation within the existing business environment (Barton, Love \& Taylor, 2001). Predefined and known cost figures for the system or component under investigation are expected to be retrieved rather than computed. For example, Romero Rojo et al. (2012) propose a model of avionic obsolescence cost for use in service-system contracts in which the base cost of resolving an obsolescence issue must be known.

\subsection{Cost is a necessary evil due to cost drivers}

Another view on cost rests on an understanding of "cost drivers" as something to drive out and get rid of or minimise. The expression "cost driver" is recurring in both literature and practice, but often misinterpreted. As Stump (1989) points out, cost drivers are often improperly used as synonyms for the cost categories in which costs are classified; the most expensive (high value) item in a product; or the quantifiable product features discussed in the previous section -like weight, etc. - which can be statistically related to the unit cost of a product. For example, 
Erkoyuncu et al. (2011) identify failure rate, turnaround time, repair cost, LRU (Line

Replaceable Unit) cost, and labour availability as “...typical cost drivers that arise at the bidding stage of a contract for availability".

287

Underpinning this view on cost is that cost drivers are decision elements that have instantaneous cash flow consequences. These decision elements are usually considered in isolation. Cooper calls these models "spending models" (Cooper, 1990). Maintenance, for example, is frequently dismissed as a necessary evil. In such view maintenance efforts are unwelcome activities that drive costs therefore they should be avoided. The positive contribution of maintenance to the final delivery of an outcome, for example sustaining production in a manufacturing plant, is simply neglected (Kelly, 2006, Sherwin, 2000). For example, Browning \& Heath (2009) demonstrate, with a case study of the F-22 production line, that cutting cost can remove the necessary conditions for successful delivery of desired outcome in the absence of an understanding how the system works.

\subsection{Cost is an emergent property of a system}

Finally, cost can be viewed as determined primarily by the dynamic behaviour of the system delivering products (or services) (Storck, 2010). In this case cost is an "emergent property", and effective cost analysis must rely upon a consistent and transparent representation of the context within which products and services are designed and delivered (Field, Kirchain \& Roth, 2007).

Similarly, van der Merwe (2007) highlights that insight is needed into the quantitative flow of goods and services consumed and produced by the enterprise, whereas money is a metalanguage providing a corresponding value representation of the quantitative flow. In this case the knowledge required for the costing operation is more than just data and information (e.g. regarding a product's cost and technical characteristics), rather, focus is on 
what the information represents, how to handle it and most importantly what action to take (Naylor, Griffiths \& Naim, 2001).

Models of virtual cost flows based on means (enabling conditions) and ends (desired outcomes) relationships within a system of interrelated operations have been developed, for example, in the field of material and energy flow costing (Möller, 2010). Another example is the application of Functional Analysis, which bases cost analysis on the functions or services provided through the activities performed within an enterprise and how they are achieved (Yoshikawa, Innes \& Mitchell, 1994).

In this view, "cost drivers" are causal events which determine "why" work takes place and how much effort must be expended to carry out the work (Emblemsvåg, 2003). They measure the frequency and intensity of the demands placed on activities performed within an organisation, hence sometimes they express the output of an activity (Raffish \& Turney, 1991).

This view of cost drivers allows initiatives for cost reduction to be centred on improved efficiency, which measures the use of resources in activities performed in order to deliver an outcome (Neely, Gregory \& Platts, 2005).

\subsection{Comparison of perspectives}

Table 1 provides a simple example of how the perspective taken towards costing may shape the understanding and action of an organisation, taking the example of the Watchkeeper UAS program. Depending on the perspective of the individual, what is being delivered by the program ranges from a quantity of unmanned aircraft to tactical intelligence. In the latter case the Watchkeeper UAS may only be one option to deliver the outcome. Therefore, the costs incurred would not be attributed to individual assets, but rather to the activities required to deliver intelligence. The achievement of certification, more precisely the time needed to get there, is an example for a program cost driver. Consequently, reducing the time to certification leads to cost reductions. 
334 This example shows that the rationale for making decisions depends on the view we have on a

335 phenomenon. Based on our perspective the meaning something has for us changes and so do 336 our options for taking action.

\section{No understanding, no action}

338 One aspect which is rarely highlighted is why a cost estimate is carried out. Table 2 presents 339 some insight derived from selected academic references.

\section{Table 2 Why cost estimation?}

341 Often, the purpose is the generation of a one-time cost estimate independent of specific organisational and industrial settings, sometimes referred to as should-cost estimating (Ellram, 1996). A limitation associated with this purpose is that insight may appear to be less important than "providing a number" that will get approval, e.g. for budgeting purposes (Keller, Collopy \& Componation, 2014). Underlying a service enterprise, also commonly referred to as Product Service System (PSS), is typically an intent to benefit from long-term strategic alliances, which requires an advanced service provider to understand the whole life cost of a PSS contract (Meier, Roy \& Seliger, 2010). The purpose of assessing the cost of an advanced service provided through a PSS should be to provide information to support taking action for continuously meeting contracted levels of performance. This is consistent with the call for a shift of focus on methods of controlling cost, "...rather than the futile attempt to predict it" (Keller, Collopy \& Componation, 2014). Crucially, information provides insight and understanding only when it is placed in context (Glazer, 1998). 
355 Figure 1 illustrates that understanding and actions are intertwined in a continuous process over time. Understanding evolves through continuous updates, taken from available environmental clues about the situation. Understanding is then tested through action in the real world to compare the expected with the actual outcome. Only when an understanding of a situation - including the interactions with the environment - is present can we determine what needs to be known to solve a problem (Ackoff, 1989). How well we understand a phenomenon determines our abilities to anticipate or infer the future behaviour of a system and accordingly whether the actions we undertake can lead to the results we desire. System understanding will only emerge through intellectual effort (Burge, 2010) and costing can only be insightful when it is based on an understanding of the whole delivery system.

Attempts to predict properties by reducing the system to characteristics of individual components, or aggregated system characteristics (e.g. Valerdi, 2011), clearly contradict the very foundation of what a system is considered to be. This is namely the inability to derive the system behaviour from its components in isolation, or by neglecting the constituent relationships. Such attempts confirm the observation made by Dekker (2011) that the analysis of systems often remains "depressingly" componential.

\subsection{Shared understanding through visualisation}

374 It is recognised that in practice it is difficult to give adequate visibility to the processes involved 375 in the delivery of the final outcome of a service system (Batista, Smart \& Maull, 2008, Datta \& Roy, 2011, Ng \& Nudurupati, 2010). They are therefore particularly prone to local adaption and pragmatism by managers tasked to deliver local goals, but whose actions can ultimately lead to 
the breakdown of the whole. Considering that through the adaption of local habits (Vaughan, 1997, Snook, 2002) informal processes develop that no longer correspond to the -well intended, but static - formulation of official, or formal processes (Christensen \& Kaufman, 2009), maintaining a dynamic common understanding of these local behaviours is imperative. The value of information, or in this particular case a cost estimate, is dependent on the meaning it has for the receiver, which is a result of social processes (Jakubik, 2011). However, from a project management perspective consensus about a situation among different stakeholders cannot be imposed; rather, it has to be built (Conklin, 2006). Pictures and diagrams, in short visualisation, are means to facilitate communication (Cooke, 1994) and to achieve a shared understanding among a larger group about the same problem domain (Bell \& Badiru, 1993, Snyder et al., 1992). Concept maps are particularly useful to illustrate relationships between elements. They can be more or less formal and may or may not exhibit a hierarchical structure. Interlinks between the elements can be in the form of prepositional phrases, such as 'is a result of', 'leads to', or the like (Davies, 2011).

The Functional Resonance Analysis Method (FRAM) (Hollnagel, 2012) is an approach, to explain outcomes by interactions between system elements. It has been developed for accident investigation and risk analysis. As such it is equipped to deal with socio-technical systems to provide insights into why and how they normally succeed and occasionally fail. One of its foundations is the assumption that success and failure exist for the same reasons. For service provision this viewpoint is highly valuable as the insights provided include the enabling conditions as well as threats for the delivery to be successful. It can capture phenomena across levels, be they individual or organisational. Hence, it is suitable for use in identifying holistic phenomena of socio-technical system (Hollnagel, 2012), such as how the adaption of local practices can lead to global misalignments and ultimately failure (Snook, 2002). 
403 The above discussion has taken us from outcomes delivered by service systems, through the

404 characteristics of systems and the reasons for estimating costs, over possible views on costs to the link between understanding and taking action, which ultimately is the purpose of cost estimation. The creation of understanding is rooted in how we make sense of the world. Perhaps, one of the most effective ways of expressing this is in the words of Dekker: "If the worldview behind these explanations remains invisible to us, [...] we will never be able to discover just how it influences our own rationalities. We will not be able to action").

Table 3 shows how our underlying epistemology shapes the way we look at phenomena and may try to tackle them through actions. It is based on two distinct frames of assumptions about the world we live in or the phenomena we want to investigate, dualism versus duality (Schultze \& Stabell, 2004). A worldview of dualism or polarities assumes either/or 
relationships. For example, success and failure are two distinctive and mutually exclusive phenomena and so are service-centric and product-centric worldviews, as well as product cost and service cost estimation techniques (for example Huang, Newnes \& Parry, 2012). These categories would be considered as complementing each other in an epistemology based on dualities. With reference to the previous examples, it has been highlighted how failure and success exist for the same reasons (Hollnagel, 2012); also it has been suggested that service system costing should exploit the commonalities between products and service rather than exacerbating their differences (Thenent, Settanni \& Newnes, 2012). Park, Geum \& Lee (2012) highlight that in the marketing orientated view on PSS products can be separated from services, whilst in engineering-oriented perspective they are organically integrated to provide the outcomes that customers want. Also, the discussion in section 2 "Why service systems have their peculiarities" has shown that service systems exhibit emergent phenomena consistent with a 'both/and' epistemology, such as the inability to gain complete knowledge about them, and success and failure being having the same roots. There is enough evidence in the literature to claim that for service systems approaches that attempt to explain the system behaviour by the characteristics of separated components only provide limited, if any, insight (Wang et al., 2013).

Table 3 Underlying epistemology: dualism versus duality (Adapted from Schultze \& Stabell, 2004)

Evidently, the views on cost discussed in section 4 "What is your cost model?" reflect different epistemological standpoints. Understanding cost as an emergent property of a system of interrelated activities (Field, Kirchain \& Roth, 2007) undertaken to achieve a purpose suggests costs being rooted in practices, how the delivery system works. Conversely, cost being considered as intrinsic property of a product is based on a direct and knowable relation

451 between the product's characteristics, for example through a breakdown structure and its 
costs (see for example Castagne et al., 2008). Similarly, cost drivers assume a direct causal relationship between specific properties of a delivery system (or product) and costs. These properties can be influenced independently of each other to achieve cost minimisation i.e. eliminate non-value adding costs (see for example Cai et al., 2008). It is the authors' opinion that the literature on costing service-systems endorses an 'either/or' epistemology (contrasting product to service cost estimation techniques) to a 'both/and' situation (a servicesystem). It does so by focusing on isolated 'pockets of comprehensive knowledge' about the technical system element (the product) of what should be considered as a socio technical system.

Such an approach is not without risk. When we take actions based on an understanding derived through an 'either/or' epistemology to a 'both/and' context we cannot expect that the situation changes in the intended way. In fact, we may easily remove the conditions for the system to deliver its function (Browning \& Heath, 2009). Therefore, before a tool for decision support is employed one should ask whether the assumptions underlying such tool are indeed appropriate for the situation at hand.

When defining the boundaries of the system of interest, a sharp distinction between complete knowledge within the boundaries, and the absence of any knowledge outside of the boundaries should not be expected. Rather, varying degrees of incomplete knowledge will shape blurred boundaries around the system under investigation. The boundaries, as stated in section 2.2 "Service systems are socio-technical systems" are reasonably defined according to the purpose of the system investigation which also drives the required knowledge within these boundaries. "Opaqueness" is the term used by George (2010) to describe the differing insights different stakeholders have about the same phenomenon, in his example business processes.

475 Depending on the knowledge required appropriate methods need to be employed. A database 476 rich of product data may not provide the desired insight into labour-intensive business 
477 processes that are shared with the customer, such as typical for service systems (Ng et al.,

478 2011). Interviews by contrast are well suited to unveil not only what is happening, but also why 479 and how things are done (Naylor, Griffiths \& Naim, 2001).

480 It is shown by George (2010) that high performing companies approach cost reduction

481

482

483

484

485 opportunities based on diagnostics and understanding, whereas average performers arbitrarily. We should therefore critically question what is known about cost and how it is known. In the absence of an agreed framework that reflects the epistemological needs of cost estimation for service systems practical advice can only be focused on how to approach a situation. Table 4 summarises the aspects discussed above to provide guidance for what needs to be known and how it can be known. To avoid applying unsuitable methods careful consideration should always be paid to the underlying assumptions about the situation at hand, as shown in Table 3.

\section{Table 4 What needs to be known to estimate the cost of a service system?}

\section{Conclusion and future work}

Management decisions are frequently based upon distinct worldviews on costs that are reinforced by experts, but insightful costing remains a challenge. As systems rather than products are procured some of the weaknesses of the standard approaches to cost modelling deserve more attention. The way a cost is to be used has an impact upon the way it might be calculated. Further, the perceptions of different managers will influence how costs are built up within a cost model and there are no guarantees that the different elements of the cost models are all built upon a shared set of common assumptions. A greater understanding of what we know and how we know it, the epistemology, is required. The relationship between underlying epistemology and cost modelling approaches shows that philosophical grounding is not just something for those in the ivory towers of academia. Instead, it has important 
practical relevance for managers as epistemology determines the chosen view on the world and accordingly influences what managers are able to do and what they may try and change. This is in line with previous findings in the field of engineering and service science (Batista, Smart \& Maull, 2008, Emblemsvåg \& Bras, 2000).

Methods to deal with these challenges are available, such as FRAM, although not in the field of cost estimation. Therefore further work is required to adapt these methods to the needs of cost estimation while retaining philosophical consistency. A case study is currently underway that aims to deliver a practical approach including a proof-of-concept of a computational structure which is based on a qualitative representation of the service system.

\section{Acknowledgements}

511 The authors gratefully acknowledge the support provided by the Department of Mechanical

512 Engineering at the University of Bath and the Engineering and Physical Sciences Research

513 Council (EPSRC) for funding the research under the Innovative electronics Manufacturing 514 Research Centre (leMRC), Grant Offer Letter SP/02/09/10, Costing For Avionics Through Life 515 Availability (CATA).

\section{References}

517 Ackoff RL. 1989. From Data To Wisdom. Journal of Applied Systems Analysis 16: 3-9

518 Anagboso M, Spence A. 2009. Measuring Defence. Economic \& Labour Market Review 3 (1): $519 \quad 44-52$

Aston Business School. 2013. Servitization impact study. How UK based manufacturing organisations are transforming themselves to compete through advanced services: Aston University, United Kindgom 
Baines T, Lightfoot H. 2013. Made to serve. How manufacturers can compete through servitization and product-service systems. Hoboken, N.J, Chichester: Wiley; John Wiley [distributor]

Bartolomei JE, Hastings DE, Neufville R de, Rhodes DH. 2012. Engineering Systems MultipleDomain Matrix: An organizing framework for modeling large-scale complex systems. Syst. Engin. 15 (1): 41-61

Barton JA, Love DM, Taylor GD. 2001. Design determines 70\% of cost? A review of implications for design evaluation. Journal of Engineering Design 12 (1): 47-58

Batista L, Smart A, Maull R. 2008. The systemic perspective of service processes: underlying theory, architecture and approach. Production Planning \& Control 19 (5): 535-44

Bell PM, Badiru AB. 1993. Concept mapping as a knowledge acquisition tool in the development of a fuzzy rule-based expert system. Computers \& Industrial Engineering 25 (1-4): 115-18. http://www.sciencedirect.com/science/article/pii/0360835293902340

Blanchard BS. 2008. System Engineering Management: John Wiley \& Sons. 4th

Boito M, Cook CR, Graser JC. 2009. Contractor logistics support in the U.S. Air Force. Santa Monica, CA: RAND

Browning TR, Heath RD. 2009. Reconceptualizing the effects of lean on production costs with evidence from the F-22 program. Journal of Operations Management 27 (1): 23-44

Burge SE. 2010. Systems Engineering. Using Systems Thinking to Design Better Aerospace Systems. In Encyclopedia of Aerospace Engineering, R Blockley, W Shyy (eds.): John Wiley \& Sons, Ltd, pp. 1-24

Cai Z, Sun S, Si S, Yannou B. 2008. Maintenance Management System Based on Bayesian Networks. International Seminar on Business and Information Management (ISBIM '08) 2: 42-45. 10.1109/ISBIM.2008.28 
547 Castagne S, Curran R, Rothwell A, Price M, Benard E, Raghunathan S. 2008. A generic tool for $548 \quad$ cost estimating in aircraft design. Research in Engineering Design 18 (4): 149-62

549 Chinn D. 2013. Preserving combat power when defense budgets are falling.

550 http://www.mckinsey.com/insights/public_sector/preserving_combat_power_when_defe 551 nse_budgets_are_falling

552 Christensen CM, Kaufman SP. 2009. Assessing your organization's capabilities: resources,

553 processes and priorities. In Strategic management of technology and innovation, RA

554 Burgelman, CM Christensen, SC Wheelwright (eds.). New York, USA: McGraw-Hill

$555 \quad$ Companies, Inc. 5th ed., pp. 153-64

556 Coghlan T. 2012. MoD turns to France as fears grow over fighter jet choice. The Times, Jan. 26:

$557 \quad 16$

558 Conklin EJ. 2006. Dialogue mapping. Building shared understanding of wicked problems.

$559 \quad$ Chichester, England, Hoboken, NJ: Wiley

560 Cooke NJ. 1994. Varieties of knowledge elicitation techniques. International Journal of Human-

$561 \quad$ Computer Studies 41 (6): 801-49.

562 http://www.sciencedirect.com/science/article/pii/S1071581984710834

Cooper R. 1990. Explicating the logic of ABC. Management Accounting 68 (10): 58-60

564

Cooper R, Slagmulder R. 2004. Achieving full-cycle cost management. SLOAN MANAGE REV 46

565 (1): 45-52

566

Coyne KP, Coyne ST, Coyne EJ, SR. 2010. When You've Got to Cut Costs Now. Harvard Business Review 88 (5): 74-82

568 Crotty M. 1998. The foundations of social research. Meaning and perspective in the research

569 process. London: Sage Publications

570 Curran R, Raghunathan S, Price M. 2004. Review of aerospace engineering cost modelling: The genetic causal approach. Prog Aerosp Sci 40 (8): 487-534 
Datta PP, Roy R. 2010. Cost modelling techniques for availability type service support contracts: A literature review and empirical study. CIRP J. Manuf. Sci. Technol. 3 (2): 14257

Datta PP, Roy R. 2011. Operations strategy for the effective delivery of integrated industrial product-service offerings: Two exploratory defence industry case studies. IJOPM 31 (5): $579-603$

Davies M. 2011. Concept mapping, mind mapping and argument mapping: what are the differences and do they matter? Higher Education 62 (3): 279-301. 10.1007/s10734-010$9387-6$

Dean EB. 1993. Why Does It Cost How Much? AIAA Paper 93-3966. Proceedings of the AIAA Aircraft Design, Systems, and Operations Meeting

Dekker SW. 2006. The field guide to understanding human error. Aldershot, England, Burlington, VT: Ashgate

Dekker SW. 2011. Drift into failure. From hunting broken components to understanding complex systems. Farnham, Burlington, VT: Ashgate Pub.

Doost RK. 1996. Input, output, outcome: simply a change in orientation. Managerial Auditing Journal 11 (7): 12-15

Edwards JB, ed. 1999. Cost management for service industries. New York: Warren, Gorham \& Lamont

Ellram LM. 1996. A Structured Method for Applying Purchasing cost Management Tools. International Journal of Purchasing \& Materials Management 32 (1): 11-19. http://search.ebscohost.com/login.aspx?direct=true \&db=buh\&AN=9602073191\&site=eho st-live

Emblemsvåg J. 2003. Life-cycle costing. Using activity-based costing and Monte Carlo methods to manage future costs and risks. Hoboken, N.J: Wiley 
597

598

599

600

601

602

603

604

605

606

607

608

609

610

611

612

613

614

615

616

617

618

619

620

Emblemsvåg J, Bras B. 2000. Process thinking - a new paradigm for science and engineering. Futures 32 (7): 635-54.

http://www.sciencedirect.com/science/article/pii/S0016328700000136

Erkoyuncu JA, Roy R, Datta PP, Wardle P, Murphy F. 2011. Service uncertainty and cost for product service systems. In Complex engineering service systems. Concepts and research, ICL Ng, GC Parry, P Wild, D McFarlane, P Tasker (eds.). Berlin: Springer, pp. 129-46

Field F, Kirchain R, Roth R. 2007. Process cost modeling: Strategic engineering and economic evaluation of materials technologies. JOM-J MIN MET MATS 59 (10): 21-32

Fulghum DA, Warwick G, Wall R, Ben-David A. 2011. Cost Fears. Aviation Week \& Space Technology 173 (10): 2-7.

http://search.ebscohost.com/login.aspx?direct=true\&db=buh\&AN=60621425\&site=ehostlive

Gabriel M. 2013. Wissen und Erkenntnis. Essay. Aus Politik und Zeitgeschichte 18-20 (63): 3-9. http://www.bpb.de/apuz/158649/wissen

GAO. 2008. Improved analysis and cost data needed to evaluate the cost-effectiveness of Performance Based Logistics. GAO-09-41 Report, Washington, DC

George MO. 2010. The lean six sigma guide to doing more with less. Cut costs, reduce waste, and lower your overhead. Hoboken, N.J: John Wiley \& Sons

Glazer R. 1998. Measuring the Knower: Towards a Theory of Knowledge Equity. California Management Review 40 (3): 175-94. http://search.ebscohost.com/login.aspx?direct=true\&db=buh\&AN=738863\&site=ehostlive

Hansen DR, Mowen MM. 2003. Cost management. Accounting and control. Mason, Ohio, USA: Thomson/South-Western. 4th ed. 
Hart CG, He Z, Sbragio R, Vlahopoulos N. 2012. An advanced cost estimation methodology for engineering systems. Syst. Engin. 15 (1): 28-40

Hollnagel E. 2012. FRAM, the functional resonance analysis method. Modelling complex sociotechnical systems. Farnham, Surrey, UK England, Burlington, VT: Ashgate

Hoyle C. 2013. UK reveals expenditure on delayed Watchkeeper programme.

$$
\text { http://www.flightglobal.com/news/articles/uk-reveals-expenditure-on-delayed- }
$$

$$
\text { watchkeeper-programme-380779/ }
$$

Huang XX, Newnes LB, Parry GC. 2012. The adaptation of product cost estimation techniques to estimate the cost of service. Int J Comput Integrated Manuf 25 (4-5): 417-31

Jakubik M. 2011. Becoming to know. Shifting the knowledge creation paradigm. Journal of knowledge management 15 (3): 374-402

Jazouli T, Sandborn P. 2011. Using PHM to meet availability-based contracting requirements. Proceedings of the Annual Conference of the Prognostics and Health Management Society

Keller S, Collopy P, Componation P. 2014. What is wrong with space system cost models? A survey and assessment of cost estimating approaches. Acta Astronautica 93 (0): 345-51. http://www.sciencedirect.com/science/article/pii/S0094576513002464

Kelly A. 2006. Plant maintenance management set. Oxford: Butterworth-Heinemann Kim S, Cohen MA, Netessine S. 2007. Performance Contracting in After-Sales Service Supply Chains. Management Science 53 (12): 1843-58. http://search.ebscohost.com/login.aspx?direct=true \&db=buh\&AN=27879629\&site=ehostlive

Kimita K, Hara T, Shimomura Y, Arai T. 2009. Cost evaluation method for service design based on Activity Based Costing. Proceedings of the 7th International Conference on Manufacturing Research (ICMR '09) 
Labro E. 2006. Is a focus on collaborative product development warranted from a cost commitment perspective? Supply Chain Management: An International Journal 11 (6): 503-09

Lindholm A, Suomala P. 2007. Learning by costing: Sharpening cost image through life cycle costing? International Journal of Productivity and Performance Management 56 (8): 65172

Makridakis SG, Wheelwright SC, Hyndman RJ. 1998. Forecasting. Methods and applications. New York: John Wiley \& Sons. 3rd ed.

McNair CJ. 1990. Interdependence and control: traditional vs. Activity-Based responsibility accounting. Journal of Cost Management 4 (2): 15-24

Meier H, Roy R, Seliger G. 2010. Industrial Product-Service Systems-IPS2. CIRP Ann-Manuf. Technol. 59 (2): 607-27

Möller A. 2010. Material and Energy Flow-Based Cost Accounting. CHEM ENG TECHNOL 33 (4): 567-72. http://dx.doi.org/10.1002/ceat.200900491

Morelli N. 2002. Designing Product/Service Systems: A Methodological Exploration. Design Issues 18 (3): 3-17. http://www.jstor.org/stable/1512062

Naylor JB, Griffiths J, Naim MM. 2001. Knowledge-based system for estimating steel plant performance. IJOPM 21 (7): 1000-19

Neely A, Gregory M, Platts K. 2005. Performance measurement system design: A literature review and research agenda. IJOPM 25 (12): 1228-63

Newnes LB, Mileham AR, Cheung WM, Marsh R, Lanham JD, Saravi ME, Bradbery RW. 2008. Predicting the whole-life cost of a product at the conceptual design stage. Journal of Engineering Design 19 (2): 99-112

Ng ICL, Nudurupati SS. 2010. Outcome-based service contracts in the defence industry mitigating the challenges. J Serv Manage 21 (5): 656-74. 

005

Ng ICL, Parry GC, Wild P, McFarlane D, Tasker P, eds. 2011b. Complex engineering service systems. Concepts and research. Berlin: Springer

Nicolai LM, Carichner GE. 2010. Fundamentals of Aircraft and Airship Design. Volume I Aircraft Design: American Institute of Aeronautics and Astronautics

Park Y, Geum Y, Lee H. 2012. Toward integration of products and services: Taxonomy and typology. Journal of Engineering and Technology Management 29 (4): 528-45. http://www.sciencedirect.com/science/article/pii/S0923474812000343

Perrow C. 1984. Normal accidents. Living with high-risk technologies. with a new afterword

Purchase V, Parry GC, Valerdi R, Nightingale D, Mills J. 2011. Enterprise Transformation: Why Transformation 1 (1): 14-33

Raffish N, Turney PBB. 1991. Glossary of Activity-based Management. Journal of Cost Management 5 (3)

Romano P, Formentini M. 2012. Designing and implementing open book accounting in buyersupplier dyads: A framework for supplier selection and motivation. Int J Prod Econ 137 (1): 68-83

Romero Rojo FJ, Roy R, Shehab E, Cheruvu K, Mason P. 2012. A cost estimating framework for electronic, electrical and electromechanical (EEE) components obsolescence within the 

use-oriented product-service systems contracts. Proceedings of the Institution of Mechanical Engineers, Part B: Journal of Engineering Manufacture 226 (1): 154-66

Rotch W. 1990. Activity-Based Costing in service industries. Journal of Cost Management 4 (2):

697 $4-14$

698

Sandborn P. 2013. Cost Analysis of Electronic Systems. Singapore: World Scientific Publishing

699 Co. Pte. Ltd.

700

Schultze U, Stabell C. 2004. Knowing What You Don't Know? Discourses and Contradictions in Knowledge Management Research. Journal of Management Studies 41 (4): 549-73

702

Settanni E, Newnes LB, Thenent NE, Parry GC, Goh YM. 2011. Through-life costing

Sherwin D. 2000. A review of overall models for maintenance management. Journal of Quality in Maintenance Engineering 6 (3): 138-64. http://dx.doi.org/10.1108/13552510010341171

Snook SA. 2002. Friendly fire. The accidental shootdown of U.S. Black Hawks over Northern

Snyder DE, McNeese MD, Zaff BS, Gomes M. 1992. Knowledge acquisition of tactical air-toground mission information using concept mapping. Proceedings of the IEEE 1992 National

Storck J. 2010. Exploring improvement trajectories with dynamic process cost modelling: a case from the steel industry. International Journal of Production Research. International Journal of Production Research 48 (12): 3493-511

Stump EJ. 1989. "Cost Driver" Confusion. Journal of Parametrics 9 (3): 11-12

Thenent NE, Settanni E, Newnes LB. 2012. Know what you need to know. The role of technological knowledge in product service systems. ESDA2012-82791. The ASME 2012 11th Biennial Conference on Engineering Systems Design and Analysis (ESDA2012), ASME:

718 ASME 
Tirole J. 2001. Corporate Governance. Econometrica 69 (1): 1-35.

http://dx.doi.org/10.1111/1468-0262.00177

Trimble S. 2013. MROAM: USAF breaks up P\&W monopoly on C-17 engine services. http://www.flightglobal.com/news/articles/mroam-usaf-breaks-up-pw-monopoly-on-c-17engine-services-384715/

Tukker A, Tischner U. 2006. Product-services as a research field: past, present and future. Reflections from a decade of research. J Clean Prod 14 (17): 1552-56. http://www.sciencedirect.com/science/article/pii/S0959652606000862

Valerdi R. 2011. Heuristics for Systems Engineering Cost Estimation. Systems Journal, IEEE. Systems Journal, IEEE DOI - 10.1109/JSYST.2010.2065131 5 (1): 91-98

Valerdi R, Merrill J, Maloney P. 2005. Cost Metrics for Unmanned Aerial Vehicles. Proceedings of the AIAA 16th Lighter-Than-Air Systems Technology Conference and Balloon Systems Conference, AIAA

van der Merwe A. 2007. Management accounting philosophy II: The cornerstones of restoration. Cost Management 21 (5): 26-33

Vaughan D. 1997. The Challenger launch decision. Risky technology, culture, and deviance at NASA. Chicago, III., USA: University of Chicago Press. Pbk. ed.

Wang J, Wang H. F., Zhang WJ, Ip W.H., Furuta K. 2013. On a Unified Definition of the Service System: What is its Identity? IEEE Systems Journal in press

Wasson CS. 2006. System Analysis, Design, and Development. Concepts, Principles, and Practices: John Wiley \& Sons

Wickson F, Carew AL, Russell AW. 2006. Transdisciplinary research: characteristics, quandaries and quality. Futures 38 (9): 1046-59. http://www.sciencedirect.com/science/article/pii/\$0016328706000553 
Wilson B. 2001. Soft systems methodology. Conceptual model building and its contribution.

744 Chichester, New York: Wiley

745

Yoshikawa T, Innes J, Mitchell F. 1994. Functional analysis of activity-based cost information.

746 Journal of Cost Management (Spring): 40-48

747 
Nils E. Thenent

750

Nils Thenent is currently involved in the Costing for Avionic Through-Life Availability

751

(CATA) at the University of Bath as a researcher. He is an aerospace engineer with expertise in the fields of avionics maintenance and aircraft design. Nils has been working with major aerospace companies, such as Lufthansa Technik, Pratt \& Whitney Canada, GE Aviation and BAE Systems, and has presented his research at national and international conferences. His research interests include research methodology, socio-technical systems, aviation safety, aircraft technology and aviation management.

Ettore Settanni

759

Ettore Settanni is a post doctoral researcher at the University of Bath and is the lead researcher in the research project Costing for Avionic Through-Life Availability (CATA) working with Defence Equipment and Support (DE\&S), GE Aviation and Military Air Information, BAE Systems. He provides inter-disciplinary methodological expertise for assessing and modelling the Through Life Costs of product-servicesystems.

Glenn Parry

767 Glenn Parry works with both multi-national and SME firms, exploring how they create and capture value with their partners and customers. The impact of his work includes a $f 5 \mathrm{k}$ SME grant which generated $f 100 \mathrm{k}$ of revenue, creating $1 \mathrm{job}$ and securing 2 others and the Lean tools for Core Competence Analysis he developed enabled the case company to increase market share from $5 \%$ to $\sim 80 \%$. Glenn has expertise in Lean, Service, Business Models and Value. He publishes in leading 
773 journals and his Paper "Music business models and piracy" was selected as one of

774 the Outstanding Papers of 2013.

775

776 Yee Mey Goh

777 Yee Mey Goh is a Senior Lecturer in Wolfson School of Mechanical and

778 Manufacturing Engineering, Loughborough University. She is an associate member

779 of the Design Society and a member of scientific committee for a number of

780 international conferences (ASME IDETC/CIE, ICED, DESIGN and EP\&DE).

781

782 Linda B. Newnes

783 Linda Newnes is Head of Costing Research at the University of Bath. She models

784 costs for the design, manufacture and use of products, such as long-life electronic

785 systems and aircraft. Her drive is to assess how to sustain the design and

786 manufacture of these products in terms of through-life-costs (TLC) and assisting

787 industry partners with capability in design, manufacturing and service. Linda has

788 embedded her research into industry - identifying a 63\% cost saving, has run

789 costing seminars for industry and currently represents academia on the Joint

790 Industry/MoD Whole Life Cost working group. She has published over 105 peer

791 reviewed papers, 2 Industrial research reports and 3 book chapters. 